\title{
Preparedness of Finnish Emergency Medical Services for Chemical Emergencies
}

\author{
Timo J. Jama, MD, MSc (EMDM); ${ }^{1}$ Markku J. Kuisma, $\mathrm{MD}, \mathrm{PhD}^{2}$
}

1. Centre for Prehospital Care and Emergency Medicine, Päijät-Häme Social and Healthcare Group, Lahti, Finland

2. Emergency Medical Services, Department of Emergency Medicine, Helsinki University Hospital, Finland

\author{
Correspondence: \\ Timo Jama, MD, MSc (EMDM) \\ Päijät-Häme Social and Healthcare Group \\ Centre for Prehospital Care and \\ Emergency Medicine \\ Keskussairaalankatu 7 \\ 15850 Lahti, Finland \\ E-mail: timo.jama@phsotey.fi
}

Conflicts of interest: none

Keywords: CBRN; chemical incidents; decontamination; EMS; preparedness
Abbreviations:
CBRN: chemical, biological, radiological, nuclear
CPAP: continuous positive airway pressure
EMS: Emergency Medical Services
HUS: University Hospital District of Helsinki and Uusimaa
IV: intravenous
NIV: non-invasive ventilation

Received: August 26, 2015

Revised: December 13, 2015

Accepted: December 22, 2015

Online publication: May 24, 2016

doi:10.1017/S1049023X16000546

\begin{abstract}
Introduction: The preparedness level of Finnish Emergency Medical Services (EMS) for treating chemical emergencies is unknown. The aim of this study was to survey the preparedness level of EMS systems for managing and handling mass-casualty chemical incidents in the prehospital phase in Finland.

Hypothesis: The study hypothesis was that university hospital districts would have better clinical capability to treat patients than would central hospital districts in terms of the number of patients treated in the field within one hour after dispatching as well as patients transported to hospital within one hour or two hours after dispatching.

Methods: This cross-sectional study was conducted as a Webropol (Wuppertal, Germany) survey. All hospital districts $(\mathrm{n}=20)$ in continental Finland were asked about their EMS preparedness level in terms of capability of treating and transporting chemically affected patients in the field. Their capability for decontamination of affected patients in the field was also inquired.

Results: University hospital district-based EMS systems had at least $20 \%$ better absolute clinical capacity than central hospital-based EMS systems for treating chemically affected patients concerning all treatments inquired about, except the capacity for non-invasive ventilation (NIV)/continuous positive airway pressure (CPAP) treatment in the field. Overall, there was a good level of preparedness for treating chemical accident patients with supplemental oxygen, bronchodilators, and inhaled corticosteroids. Preparedness for providing antidote therapy in cases of cyanide gas exposure was, in general, low. The variation among the hospital districts was remarkable. Only nine of 15 central hospital district EMS had a mobile decontamination unit available, whereas four of five university hospital districts had one.

Conclusion: Emergency Medical Services capacity in Finland for treating chemically affected patients in the field needs to be improved, especially in terms of antidote therapy. Mobile decontamination units should be available in all hospital districts.
\end{abstract}

Jama TJ, Kuisma MJ. Preparedness of Finnish Emergency Medical Services for chemical emergencies. Prehosp Disaster Med. 2016;31(4):392-396.

\section{Introduction}

Environmentally hazardous materials usually are grouped according to the type of threat they pose: chemical, biological, radiological, or nuclear (CBRN) ${ }^{1,2}$ A chemical substance release may be accidental or it may be deliberate and intended to harm people. ${ }^{3,4}$ Of CBRN threats, chemical substances can be considered the most challenging because of the rapid onset of action and potentially lethal consequences within minutes. ${ }^{5}$ First responders are often Emergency Medical Services (EMS) providers. ${ }^{6}$ Careful planning, training, and preparedness are the key components in the successful management of mass-chemical incidents, both in hospitals and in the field by EMS providers. ${ }^{2,4,7,8}$ However, there are frequent reports of a lack of preparedness and EMS provider training for chemical mass-casualty situations. ${ }^{9-13}$

The level of Finnish EMS preparedness for chemical mass-casualty situations is unknown. The aim of this study was to assess the current level of preparedness of the Finnish EMS for responding to chemical mass-casualty situations in Finland. The results can be utilized for improving the EMS preparedness for such situations in Finland. 


\begin{tabular}{|c|c|c|c|c|c|c|}
\hline Hospital District & Population $^{\mathbf{a}}$ & $\begin{array}{l}\text { Total Area } \\
\left(\mathbf{k m}^{2}\right)\end{array}$ & $\begin{array}{l}\text { Population } \\
\text { Density }\end{array}$ & $\begin{array}{c}\text { Number of } \\
\text { Ambulances }^{b}\end{array}$ & $\begin{array}{l}\text { Ambulance Density per } \\
10,000 \text { Inhabitants }\end{array}$ & $\begin{array}{c}\text { Ambulance Density } \\
\text { per } 1000 \mathrm{~km}^{2}\end{array}$ \\
\hline $\begin{array}{l}\text { Central- } \\
\text { Ostrobothnia }\end{array}$ & 78,395 & 7,719 & 10.16 & 13 & 1.66 & 1.68 \\
\hline Central Finland & 251,178 & 19,949 & 12.59 & 33 & 1.31 & 1.65 \\
\hline Etelä-Savo & 103,873 & 19,130 & 5.43 & 17 & 1.64 & 0.89 \\
\hline $\begin{array}{l}\text { Helsinki and } \\
\text { Uusimaac }^{c}\end{array}$ & $1,599,390$ & 15,707 & 101.83 & 72 & 0.45 & 4.58 \\
\hline Itä-Savo & 44,051 & 5,711 & 7.71 & 7 & 1.59 & 1.23 \\
\hline Kainuu & 76,119 & 24,451 & 3.11 & 14 & 1.84 & 0.57 \\
\hline Kanta-Häme & 175,350 & 5,708 & 30.72 & 17 & 0.97 & 2.98 \\
\hline Kymenlaakso & 172,908 & 7,456 & 23.19 & 16 & 0.93 & 2.15 \\
\hline Lappi & 118,145 & 100,367 & 1.18 & 29 & 2.45 & 0.29 \\
\hline Länsi-Pohja & 63,603 & 8,634 & 7.37 & 11 & 1.73 & 1.27 \\
\hline North Karelia & 168,896 & 21,584 & 7.83 & 24 & 1.42 & 1.11 \\
\hline $\begin{array}{l}\text { North } \\
\text { Ostrobothnia }^{c}\end{array}$ & 405,635 & 45,350 & 8.94 & 41 & 1.01 & 0.90 \\
\hline Pirkanmaa $^{\mathrm{C}}$ & 524,447 & 14,613 & 35.89 & 39 & 0.74 & 2.67 \\
\hline Pohjois-Savo ${ }^{c}$ & 248,407 & 20,366 & 12.20 & 29 & 1.17 & 1.42 \\
\hline Päijät-Häme & 212,957 & 6,255 & 34.05 & 20 & 0.94 & 3.20 \\
\hline Satakunta & 223,983 & 11,493 & 19.49 & 24 & 1.07 & 2.09 \\
\hline South Karelia & 131,764 & 6,872 & 19.17 & 11 & 0.83 & 1.60 \\
\hline $\begin{array}{l}\text { South } \\
\text { Ostrobothnia }\end{array}$ & 198,242 & 14,356 & 13.81 & 21 & 1.06 & 1.46 \\
\hline Vaasa & 169,652 & 17,081 & 9.93 & 15 & 0.88 & 0.88 \\
\hline $\begin{array}{l}\text { Varsinais- } \\
\text { Suomi }^{\mathrm{C}}\end{array}$ & 475,842 & 20,902 & 22.77 & 34 & 0.71 & 1.63 \\
\hline
\end{tabular}

Table 1. Characteristics of Hospital Districts in Finland

(Note: Source - http://www.localfinland.fi/en/Pages/default.aspx.)

${ }^{a}$ At the end of 2014.

${ }^{\mathrm{b}}$ Full-time and part-time units.

${ }^{\mathrm{c}}$ University Hospital Districts.

This study was a cross-sectional survey. The publication is the result of a thesis submitted in partial fulfilment of the requirements for the degree of Master of Science in Disaster Medicine (European Master in Disaster Medicine) by the first author.

\section{Materials and Methods}

Finland is divided into 20 independent hospital districts that are each responsible for arranging EMS for their region under Finnish health care legislation. Five of these districts are university hospital-based and the rest are central hospital-based. Under Finnish legislation, at least one medical director is required in each district to supervise and control the EMS system. Demographics of each hospital district and EMS are shown in Table 1.
The study hypothesis was that university hospital districts have at least $20 \%$ better EMS preparedness, quantitatively, for treating chemically injured patients in the field than do non-university hospital districts.

The survey was conducted via the electronic Webropol 2.0 (Wuppertal, Germany) online platform. Webropol is a web-based tool for creating electronic questionnaires. The validity of the questions in the study questionnaire was tested in July 2014 by three medical directors. The final study questionnaire was sent as a Webropol survey to all the medical directors of the EMS $(n=26)$ in Finland in September 2014, excepting those who had already responded during the validation phase. These medical directors were asked to evaluate their own regional EMS's capacity and preparedness for chemical threats and accidents. The study 


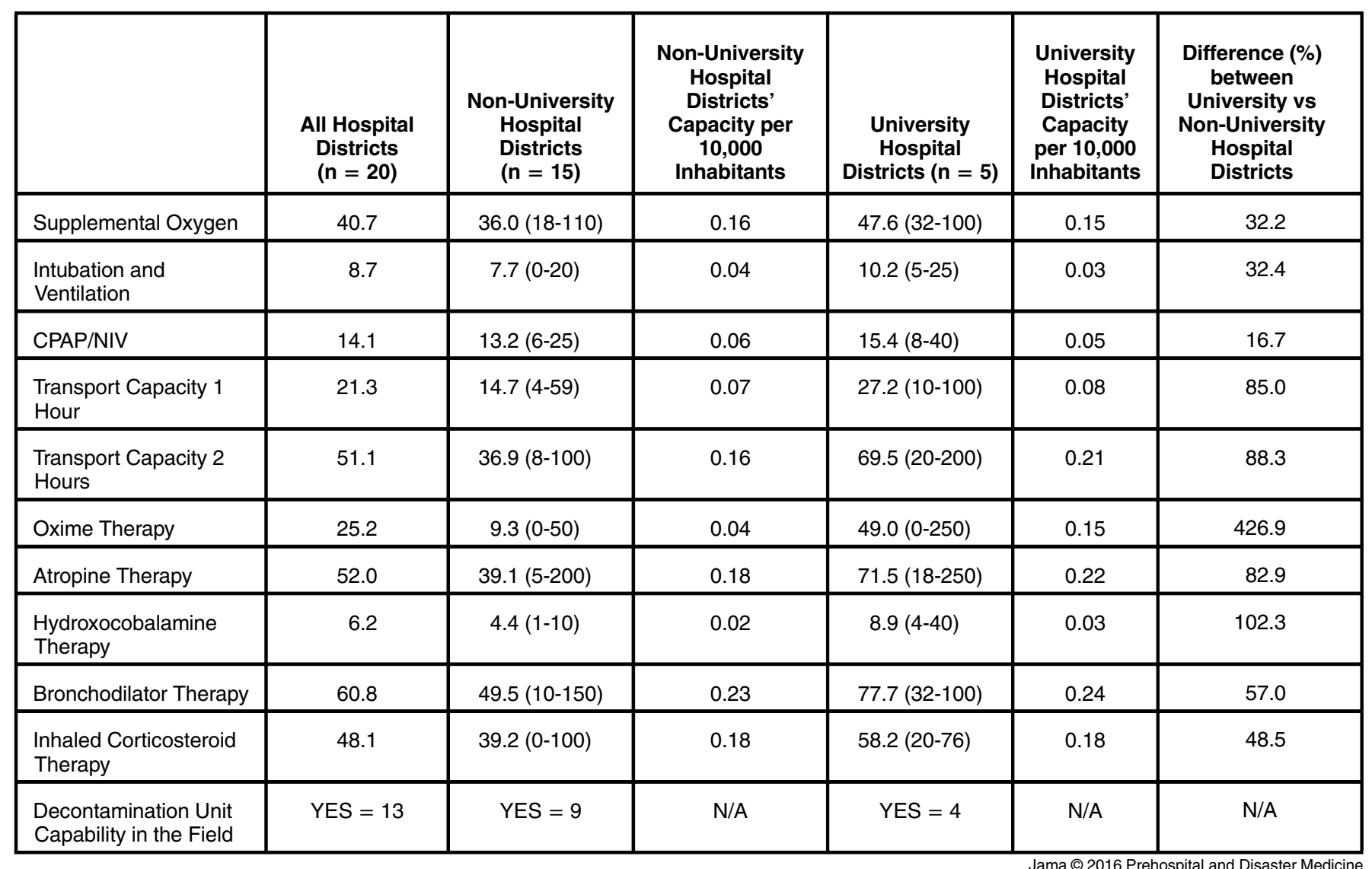

Table 2. Absolute Number of Patients the EMS is Capable of Treating in the Field within One Hour (mean $(\min -\max ))$ and

Treatment Capacity per 10,000 Inhabitants

(Note: Decontamination unit capability is reported as the number of hospital districts in which it is available.)

Abbreviations: CPAP, continuous positive airway pressure; EMS, Emergency Medical Services; NIV, non-invasive ventilation.

questions were scenario-based (Appendix; available online only) and structured on three common, world-wide, chemical threats: choline esterase inhibitors (organophosphates), asphyxiates (cyanide gas), and pulmonary irritants (ammonium gas). In addition, the medical directors were asked to estimate the number of patients their regional EMS would be capable of treating with supplemental oxygen, to evaluate their EMS's capacity to intubate and ventilate patients in the field, and to evaluate the EMS's transport capacity. Decontamination preparedness was also inquired. The medical directors were asked to evaluate their EMS's capacity for treatment within one hour after dispatch and their capacity for transport within one and two hours after dispatch. The accident site in each scenario was defined to be at a distance of five kilometers from the regional treating hospital. In addition to their daily EMS resources, the medical directors were also asked to include and evaluate the supplemental resources of their mass-casualty incident plans as operative in the field.

As the response rate was low for the first questionnaire (50\%), a reminder was sent to non-responders in December 2014, inviting them again to participate in the study.

The results were transferred from the Webropol 2.0 database to MS Excel (Microsoft Corporation; Redmond, Washington USA) spreadsheet version 14.0.7153.5000 for analysis. Each question was analyzed for mean, maximum, and minimum and compared in three groups: all hospital districts, university hospital districts, and non-university hospital districts (Table 2). The University
Hospital District of Helsinki and Uusimaa (HUS; 24 municipalities, Finland) is different from the others because it is divided into seven sub-districts; however, the results of HUS are reported here as those of one district.

No patient identification or personal data were used in the study.

\section{Results}

The response rate was $100 \%(20 / 20)$. Results are summarized in Table 2.

\section{Supplemental Oxygen}

Mean capacity for treating affected patients with supplemental oxygen within one hour was 36.0 patients for non-university hospital districts and 47.6 patients for university hospital districts.

\section{Intubation and Ventilation}

Non-university hospital districts were able to intubate and ventilate 7.7 patients in the field within one hour and university hospital districts were able to treat 10.2 patients.

\section{Continuous Positive Airway Pressure (CPAP)/Non-invasive} Ventilation (NIV)

Mean capacity for prehospital non-invasive ventilation support (NIV) or continuous positive airway pressure (CPAP) therapy 
within one hour was 13.2 patients for non-university hospital districts and 15.4 for university hospital districts.

\section{Oxime Therapy}

Mean treatment capacity for prehospital oxime therapy (obidoxime $250 \mathrm{mg}$ intravenous [IV]/intramuscular) within one hour was 9.3 patients for non-university hospital districts and 49.0 for university hospital districts.

\section{Atropine Therapy}

Mean treatment capacity for atropinization (at least $2.0 \mathrm{mg}$ dose IV) in the field within one hour was 39.1 patients for nonuniversity hospital districts and 71.5 for university hospital districts.

\section{Cyanide Antidote Therapy}

All districts used hydroxocobalamine as the first antidote for cyanide. Mean treatment capacity ( $5.0 \mathrm{~g}$ dose) for cyanide intoxication was 4.4 patients for non-university hospital districts and 8.9 for university hospital districts. Four non-university hospital districts had, in addition, amyl nitrate in operative use in the field, and one had sodium thiosulphate as well. Only one university hospital district reported another supplement antidote (sodium thiosulphate) to be in use in the field.

\section{Inhaled Bronchodilator Therapy}

Mean treatment capacity for obstructive pulmonary irritants (such as ammonium gas) by inhaled bronchodilators within one hour in the field was 49.5 patients for non-university hospital districts and 77.7 for university hospital districts.

\section{Inhaled Corticosteroid Therapy}

Mean treatment capacity for pulmonary irritants by inhaled corticosteroid (budesonide) within one hour was 39.2 patients for non-university hospital districts and 58.2 for university hospital districts.

\section{Field Decontamination}

Sixty percent $(n=9)$ of non-university hospital districts were prepared to dispatch a mobile decontamination unit to the field while $80 \%$ of university hospital districts were prepared to do so $(n=4)$. These decontamination units were operated by the fire department in all districts that had such field capability.

\section{Transport Capacity}

Mean transport capacity from accident site to hospital for nonuniversity hospital districts was 14.7 patients within one hour and 36.9 patients within two hours; for university hospital districts it was 27.2 patients within one hour and 69.5 patients within two hours.

\section{Discussion}

There was a clear trend that EMS preparedness for managing chemical emergencies was better in university hospital districts than in central hospital districts in terms of absolute number of treated patients in the field. A particularly great difference was noticed in the treatment capacity for oxime therapy ( $427 \%$ better), hydroxocobalamine therapy (102\%), atropine therapy (83\%), and transport capacity (85\%-88\%). Only the capacity for CPAP/NIV treatment in the field $(16.7 \%$ better) was under the $20 \%$ level which was preset in the study hypothesis for university hospital districts. When focusing on treatment capacity per 10,000 inhabitants, the differences between university hospital districts vs central hospital districts were lower (Table 2).

Emergency Medical Services should have strong knowledge and preparedness levels for responding adequately and quickly to chemical accidents and deliberate releases of toxic substances. The cornerstones of successful prehospital management of chemical mass-casualty situations include the rapid identification of the substance, personal protective equipment and its proper use, decontamination, proper triage, and Basic and Advanced Life Support and antidote therapy, if indicated. ${ }^{2,4,7,14,15}$ The identification of toxins can be challenging in the field. There, the concept of toxidrome may help EMS providers. ${ }^{16,17}$ Field triage of chemically injured patients differs from normal trauma triage. A method has been proposed for CBRN triage, ${ }^{18,19}$ but it has not been validated. ${ }^{20}$

Lessons learned focus on preparedness of EMS and hospitals for chemical mass-casualty situations and disasters. The lack of decontamination possibilities affects prehospital care providers and hospital staff, placing them at higher risk of exposure to potentially lethal chemicals and at higher risk of becoming victims themselves. ${ }^{21-23}$ The same challenge has been observed in most European countries as well. ${ }^{24}$

\section{Limitations}

This study was a survey and the numbers given by the respondents were estimates. Despite having the best knowledge of their EMS capacity, the medical directors may under- or over-estimate their regional EMS capacity. This can lead to bias. It was not possible to reduce this by this study design. Results may, in addition, vary by time of day (office hours or at night), by seasonal reasons (reduced holiday or weekend preparedness), or by the overcrowding of a local EMS system.

All hospital districts in Finland are unique: their geographical areas are unique, population densities vary, and their EMS organizations are different, as are their resources and the locations of their receiving hospitals. An accident site set at five kilometers from the treating hospital was chosen in order to standardize the transport time. According to the hospital districts' own risk analyses, non-standardized distances would give different results due to the geographical diversity of the EMS units.

\section{Conclusions}

Emergency Medical Services capacity in Finland for treating chemically affected patients in the field needs to be improved, especially in terms of antidote therapy. Preparedness for administering antidote therapy for cyanide gas exposure was, in general, low. Overall, there was a good level of preparedness for treating chemical accident patients with supplemental oxygen, bronchodilators, and inhaled corticosteroids. University hospital-based districts were better prepared for treating chemically affected patients in the term of absolute treatment capacity, but the differences were moderate when considering relative capacity. The variation among the hospital districts was remarkable.

Decontamination preparedness in the field in Finland urgently needs to be improved, especially in non-university hospital districts. Mobile decontamination units are recommended for all hospital districts in Finland.

\section{Supplementary material}

To view supplementary material for this article, please visit http:// dx.doi.org/10.1017/S1049023X16000546 
References

1. Thornton R, Court B, Meara J, et al. Chemical, biological, radiological, and nuclear terrorism: an introduction for occupational physicians. Occup Med (Lond). 2004; 54(2):101-109.

2. Barelli A, Biondi I, Soave M, et al. The comprehensive medical preparedness in chemical emergencies: the chain of chemical survival. Eur J Emerg Med. 2008; 15(2):110-118.

3. Baker D. Civilian exposure to toxic agents: emergency medical response. Prehosp Disaster Med. 2004;19(2):174-178.

4. Kales SN, Christiani DC. Acute chemical emergencies. N Engl J Med. 2004; 350(8):800-808.

5. Chilcott RP. Managing mass casualties and decontamination. Environ Int. 2014;72:37-45.

6. Thompson J, Rehn M, Lossius HM, Lockey D. Risks to emergency medical responders at terrorist incidents: a narrative review of the medical literature. Crit Care. 2014;18(5):521.

7. Kirk MA, Deaton ML. Bringing order out of chaos: effective strategies for medical response to mass chemical exposure. Emerg Med Clin North Am. 2007;25(2):527-548.

8. Kenar L, Karayilanoglu T. Prehospital management and medical intervention after a chemical attack. Emerg Med J. 2004;21(1):84-88.

9. Kollek D, Welsford M, Wanger K. Chemical, biological, radiological, and nuclear preparedness training for emergency medical services providers. CJEM. 2009; 11(4):337-342.

10. Barach P, Rivkind A, Israeli A, et al. Emergency preparedness and response in Israel during the Gulf War. Ann Emerg Med. 1998;32(2):224-233.

11. Phelps S. Mission failure: Emergency Medical Services response to chemical, biological, radiological, nuclear and explosive events. Prehosp Disaster Med. 2007; 22(4):293-296.

12. Chaput CJ, Deluhery MR, Stake CE, et al. Disaster training for prehospital providers. Prehosp Emerg Care. 2007;11(4):458-465.
13. Van der Woude I, Cock JS, Bierens JJLM, et al. TAP CBRN preparedness: knowledge, training, and networks. Prehosp Disaster Med. 2008;23(4): s65-s69.

14. Hulse EJ, Davies JOJ, Simpson AJ, et al. Respiratory complications of organophosphorus nerve agent and insecticide poisoning. Am J Resp Crit Care Med. 2014; 190(12):1342-1354.

15. Holland MG, Cawthon D. Personal protective equipment and decontamination of adults and children. Emerg Med Clin North Am. 2015;33(1):51-86.

16. Holstege CP, Borek HA. Toxidromes. Crit Care Clin. 2012;28(4):479-498.

17. Tomassoni AJ, French RNE, Walter FG. Toxic industrial chemicals and chemical weapons: exposure, identification, and management by syndrome. Emerg Med Clin North Am. 2015;33(1):13-36.

18. Cone DC, Koenig KL. Mass casualty triage in the chemical, biological, radiological, or nuclear environment. Eur J Emerg Med. 2005;12(6):287-302.

19. Cone DC, MacMillan DS, Parwani V, Van Gelder C. Pilot test of a proposed chemical/biological/radiation/nuclear-capable mass casualty triage system. Prehosp Emerg Care. 2008;12(2):236-240.

20. Culley JM, Svendsen E. A review of the literature on the validity of mass casualty triage systems with a focus on chemical exposures. Am J Disaster Med. 2014;9(2): 137-150.

21. Tokuda Y, Kikuchi M, Takahashi O, Stein GH. Prehospital management of sarin nerve gas terrorism in urban settings: 10 years of progress after the Tokyo subway sarin attack. Resuscitation. 2006;68(2):193-202.

22. Nakajima T, Sato S, Morita H, Yanagisawa N. Sarin poisoning of a rescue team in the Matsumoto sarin incident in Japan. Occup Environ Med. 1997;54(10):697-701.

23. Okumura T, Suzuki K, Fukuda A, et al. The Tokyo subway sarin attack: disaster management. Part 2: hospital response. Acad Emerg Med. 1998;5(6):618-624.

24. Domres BD, Rashid A, Grundgeiger J, et al. European survey on decontamination in mass casualty incidents. Am J Disaster Med. 2009;4(3):147-152. 